\title{
Сопротивление и термоэдс углеродных волокон при смене типа проводимости
}

\author{
(C) Д.К. Иванов ${ }^{1}$, К.Г. Иванов ${ }^{1, \uparrow, ~ О . Н . ~ У р ю п и н ~}{ }^{2}$ \\ ${ }^{1}$ Санкт-Петербургский государственный университет промышленных технологий и дизайна, \\ 191186 Санкт-Петербург, Россия \\ ${ }^{2}$ Физико-технический институт им. А.Ф. Иоффе Российской академии наук, \\ 194021 Санкт-Петербург, Россия \\ ฯ E-mail: Kivanov@mail.ru
}

(Получена 27 декабря 2016 г. Принята к печати 12 января 2017 г.)

Установлено, что после воздействия импульсного тока на углеродное волокно, последнее изменяет знак термоэдс с отрицательного на положительный. Энергия активации проводимости для исходного волокна $n$-типа составляет 60 мэВ, для модифицированного в $p$-тип 16 мэВ. Ткань из углеродных волокон с набором $p-n$-переходов не требует коммутационных пластин. В вакууме или в инертной среде углеродные волокна выдерживают нагрев до $3500 \mathrm{~K}$, что открывает возможность создания термоэлектрических генераторов на больших градиентах температур.

DOI: $10.21883 /$ FTP.2017.07.44629.15

При исследовании зависимости сопротивления графитированных углеродных волокон (ГУВ) марки Tenax ${ }^{\mathrm{R}}$ HTS 5331 от величины импульсных токов [1] было установлено, что исходное волокно с проводимостью $n$-типа после воздействия импульсного тока приобретает проводимость $p$-типа. Исследования в данной работе показали, что тип проводимости изменяет только импульсный ток как в среде окислителя (на воздухе), так и в вакууме, а нагрев до высоких температур постоянным током этого результата не дает. Этот эффект побудил интерес к проведению исследований ГУВ с разной проводимостью. В данной работе измерены температурные зависимости термоэдс $(S)$ и электрического сопротивления $(R)$ ГУВ $n$-типа и, полученного из него, ГУВ $p$-типа.

Термостойкость ГУВ в окисляющих средах сохраняется до 670-720 K, поэтому разогрев ГУВ постоянным током осуществлялся от комнатной температуры до 650 К. Измерения температуры проводились хромельалюмелевой термопарой. Зависимость сопротивления ГУВ от температуры носит полупроводниковый характер (рис. 1), так как сопротивление с ростом температуры убывает.

Знак термоэдс ГУВ до пропускания импульсного тока отрицателен при комнатной температуре и выше, что указывает на доминирующий вклад электронов в электроперенос. После пропускания импульсного тока через ГУВ знак термоэдс становится положительным. Происходит смена электронного типа проводимости на дырочный. Изменение сопротивления ГУВ с температурой описывается стандартной экспоненциальной зависимостью:

$$
R=A \exp \left(E_{A} / k_{\mathrm{B}} T\right),
$$

где $E_{A}-$ энергия активации электрической проводимости, $k_{\mathrm{B}}-$ постоянная Больцмана, $T-$ абсолютная температура, $A-$ некоторая постоянная. В соответствии с этим, логарифм экспериментально измеренного со- противления линейно зависит от обратной температуры (рис. 2). По наклону этих зависимостей определены значения энергии активации, которые для $n$-типа составляют $E_{A, n}=60$ мэВ и для $p$-типа $E_{A, p}=16$ мэВ. Удельное сопротивление ГУВ при комнатной температуре для $n$-типа равно $9.0 \cdot 10^{-5} \mathrm{OM} \cdot \mathrm{M}$, для $p$-типа $3.9 \cdot 10^{-5} \mathrm{OM} \cdot \mathrm{M}$.

На рис. 3 и 4 представлены результаты измерения температурной зависимости термоэдс ГУВ $p$ - и $n$-типа. Приблизительно до $250 \mathrm{~K}$ у ГУВ $р$-типа наблюдается линейный ход термоэдс от температуры (рис. 3). Затем термоэдс достигает максимума и начинает уменьшаться. На температурной зависимости термоэдс ГУВ $n$-типа (рис. 4) также есть линейный участок, начинающийся с $T=200 \mathrm{~K}$. Ниже этой температуры значения термоэдс выходят на минимум. Наличие линейных участков на температурной зависимости термоэдс свойственно металлам.

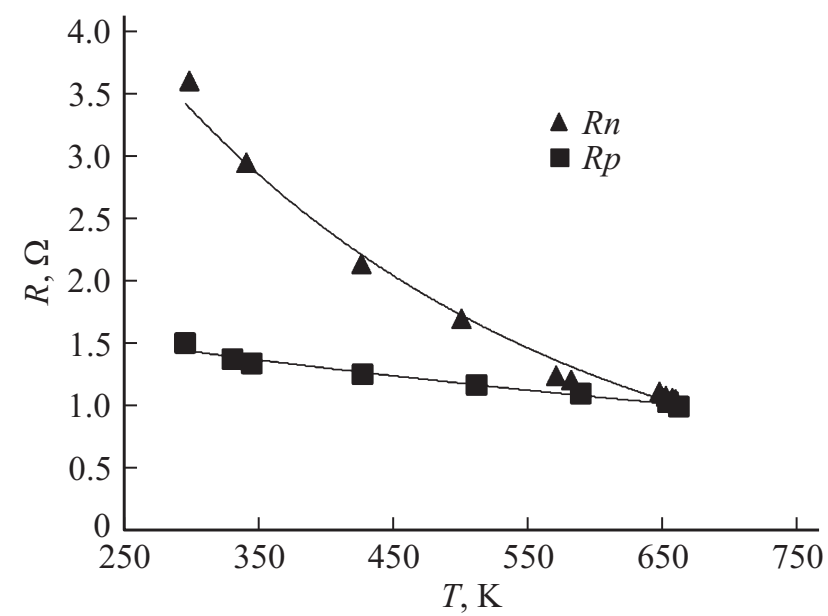

Рис. 1. Температурные зависимости сопротивления ГУВ $n$ и $p$-типа. Разогрев волокна происходит под воздействием постоянного тока. 


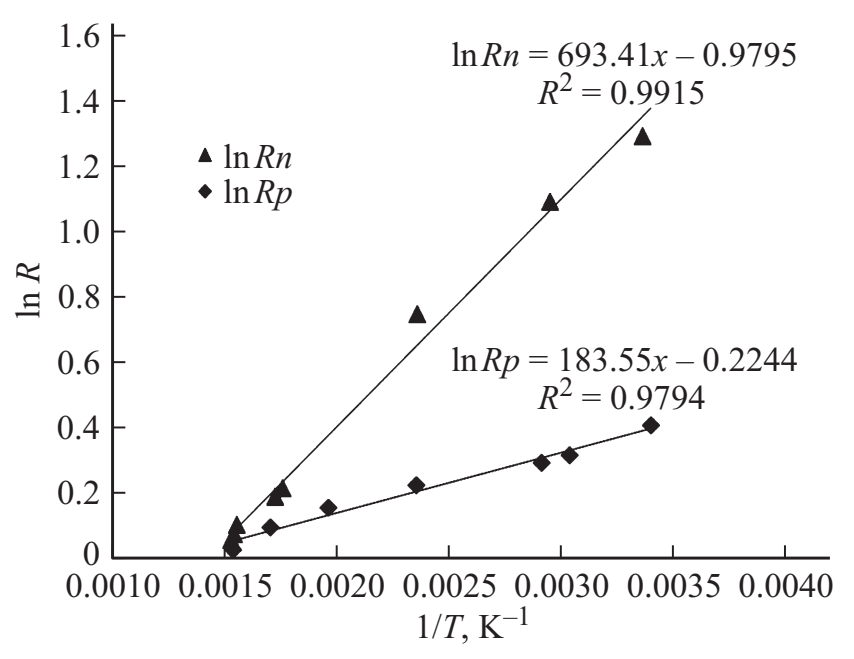

Рис. 2. Зависимость логарифма сопротивления для $p$ - и $n$-типа ГУВ от обратной температуры в пределах от 300 до $650 \mathrm{~K}$.

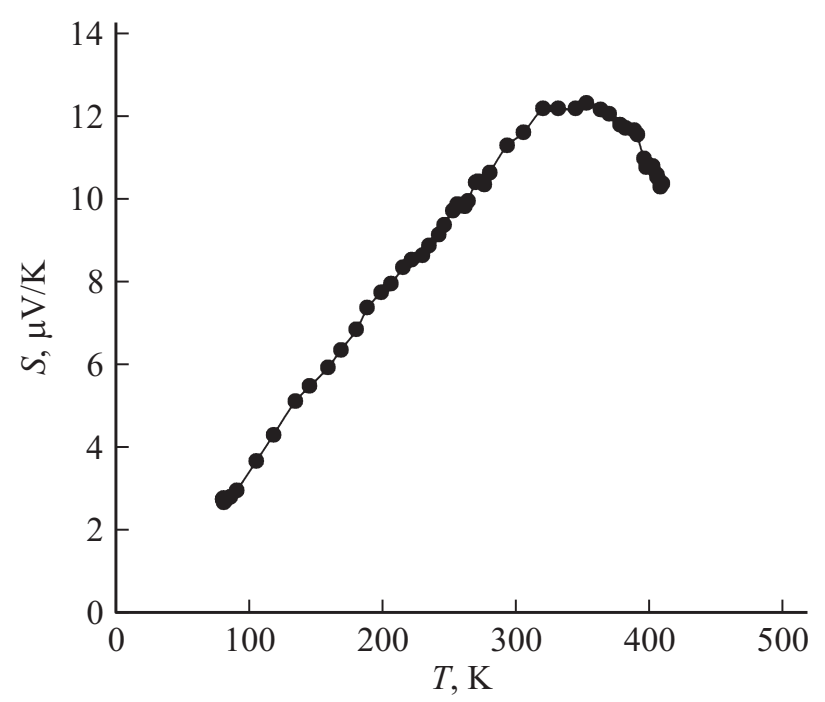

Рис. 3. Зависимость термоэдс от температуры для ГУВ $p$-типа.

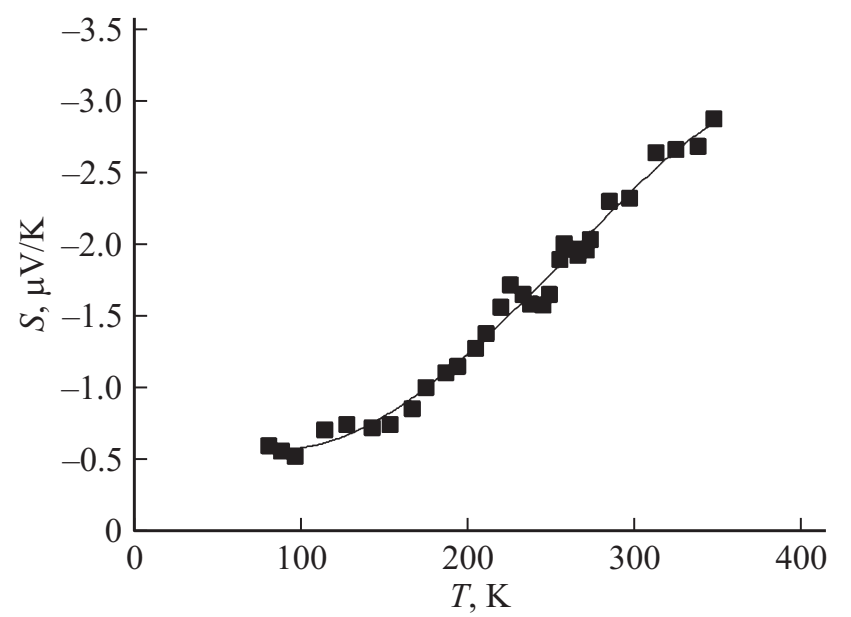

Рис. 4. Зависимость термоэдс от температуры для ГУВ $n$-типа.
Используемые волокна, возможно, содержат большое количество примесей, которые могут быть по отношению к углероду как донорами, так и акцепторами. При пропускании импульсных токов происходит кратковременный, но очень сильный разогрев волокна, который устраняет (испаряет) примеси донорного типа, и это может приводить к смене знака термоэдс.

Термоэдс на волокнах $p$-типа в температурном интервале от 80 до $347 \mathrm{~K}$ превышает термоэдс волокон $n$-типа по абсолютной величине: минимально в 3.7 раза при $245 \mathrm{~K}$ и максимально в 5.5 раз при $81 \mathrm{~K}$. Как следует из найденных выше значений, энергия активации ГУВ $n$-типа в 3.8 превышает эту величину для волокон $p$-типа.

В работах [2,3] развита гетерогенная модель электропроводности углеродных волокон. Показано, что предположение о наличии двух фаз в составе волокна: квазиметаллической и неупорядоченной или диэлектрической может объяснить все особенности проводимости УВ.

В термоэлектрических генераторных и охладительных модулях $p-n$-переход представляет собой пару ветвей, состоящих из полупроводников с разным типом проводимости, соединенных металлической коммутационной пластиной. Получение серии $p-n$-переходов на ленте из ГУВ не требует соединения волокна $p$-типа с волокном $n$-типа, так как один тип ГУВ переходит в другой по длине ленты. Нагрев до температуры $700 \mathrm{~K}$ полученного на ГУВ $p-n$-перехода, в котором происходит сложение термоэдс, дает значение напряжения порядка 8 мВ.

В вакууме или в инертной среде ГУВ выдерживают температуры до $3500 \mathrm{~K}$, что открывает возможность создания термоэлементов для работы на очень больших градиентах. Ткани из лент ГУВ с $p-n$-переходами при их параллельно-последовательном соединении и больших площадях поверхности, несмотря на очень низкую термоэлектрическую добротность, могут дать значительные мощности и открыть новые области применения подобных термоэлектрических преобразователей.

\section{Список литературы}

[1] К.Г. Иванов, А.П. Щербаков, Д.К. Иванов. Прикл. физика, 3, 47 (2015).

[2] И.А. Мисуркин, С.В. Титов, М.М. Деев, Т.С. Журавлева. Физ. химия, 75 (2), 356 (2001).

[3] Т.С. Журавлева, И.В. Клименко, С.Б. Бибиков, И.А. Мисуркин, С.В. Титов. Физ. химия, 77 (10), 1912 (2003).

Редактор Г.А. Оганесян 


\section{Resistance and thermopower of carbon fibers when changing the conductivity type}

D.K. Ivanov ${ }^{1}$, K.G. Ivanov ${ }^{1}$, O.N. Uryupin ${ }^{2}$

${ }^{1}$ St. Petersburg State University

of Industrial Technology and Design,

191186 St. Petersburg, Russia

2 loffe Institute,

194021 St. Petersburg, Russia

Abstract The work established that after exposure to pulsed current on the carbon fiber, the latter changes the sign of the thermopower from negative to positive. The activation energy of conductivity for the source fiber and the $n$-type is $60 \mathrm{meV}$ for the modified $p$-type $16 \mathrm{meV}$. The fabric of carbon fibers with a set of $p-n$-junctions not require switching plates. In a vacuum or in an inert atmosphere of carbon fiber withstand heating up to $3500 \mathrm{~K}$, allowing the creation of thermoelectric generators in large temperature gradients. 